\title{
Application of New Energy Logistics Vehicle Based on Urban Distribution
}

\author{
Long Ying $\mathrm{Li}^{1}{ }^{*}$, Jie Chen ${ }^{1}$, Yan Ping Sun ${ }^{1}$, Zhi Ying Fan ${ }^{1}$, Yu Xin Ren ${ }^{1}$ and Rui Wen Yan ${ }^{1}$ \\ ${ }^{1}$ Logistics engineering, Shan Dong Jiao Tong University, Jinan, Shan Dong Province, 250357, China
}

\begin{abstract}
With the development of the Internet era, urban logistics distribution increases. At the same time, the state vigorously promotes the development of the new energy automobile industry and the continuous strengthening of people's awareness of environmental protection, new energy vehicles began to be favored by logistics enterprises. From the analysis of the national support policy for new energy vehicles, the development of new energy vehicles in recent years and the TCO calculation of their cost advantages, this paper clarifies that new energy vehicles will occupy the mainstream position in urban logistics distribution.
\end{abstract}

\section{Introduction}

From a low - carbon perspective, Through the optimization of urban logistics distribution vehicles, new energy distribution vehicles are introduced to realize lowcarbon environmental protection of urban transportation and the sustainable development of urban logistics industry. The application of new energy logistics vehicle is an important index of green freight demonstration city. New energy logistics vehicles have been used in various subdivisions of urban distribution. Urban distribution is the main scene of the application of new energy logistics vehicle. It has the characteristics of short distance, low speed and low performance, which accords with the current development stage of new energy logistics vehicle. New energy logistics vehicles have been widely used in express delivery, e-commerce, fast retail fresh cold chain logistics and other subdivision areas of urban freight.

\section{National industrial policy to promote the development of new energy logistics vehicles}

\subsection{Urban logistics and distribution}

Under the low-carbon concept, many vehicles adopt renewable clean energy to fully achieve low carbon. In the urban logistics and distribution network, some high pollution, high energy consumption of the number of distribution vehicles more, many distribution vehicles in order to be able to increase the carrying capacity, unreasonable transformation of vehicles, so that there are many types of vehicles. First, the vehicle has limited travel time. Second, in order to be able to complete the intensive distribution tasks, vehicles need a large number of times, high carrying and high-speed driving, load and speed is an important factor affecting vehicle emissions, so that emissions continue to increase. In order to effectively control emissions, reasonable control of vehicle speed and carrying capacity is required.

\subsection{The national industrial policy promotes the development of new energy logistics vehicles}

Local governments promote the development of new energy logistics vehicles according to regional policies. Extension policies are broadly divided into two categories. The first category is to encourage enterprises to replace new energy logistics vehicles through subsidies, road rights and other measures. The second category is to limit the convenience of enterprises to use fuel vehicles by further controlling the road rights of fuel vehicles, new fuel vehicle licences, operating permits, etc. The degree of promotion as shown in Fig. 1

\footnotetext{
*Corresponding author: a1797654176@qq.com

b2587124890@qq.com

2063792570@qq.com

1455243099@qq.com

857498611@qq.com

2249720875@qq.com
} 


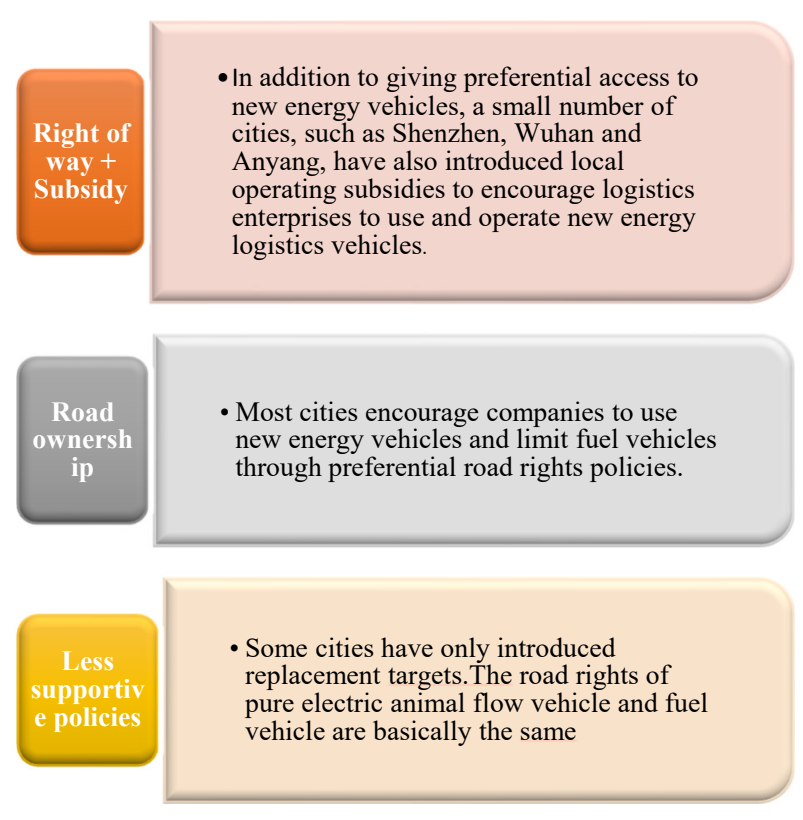

Fig. 1. Regional Policy Extension

\subsection{Analysis of the development of new energy vehicles}

Shenzhen, Guangzhou, Beijing and other economically developed, better infrastructure of the first-tier cities overall sales are still leading. In 2020, Shenzhen sold more than 10,000 vehicles, the market share of 22.15 percent, Chengdu sales exceeded 5,000 units, the market accounted for 9 percent.

TOP5 cities have sold a total of 27,789 vehicles, accounting for 47.87 percent of the market; TOP10 cities have sold a total of 37,092 vehicles, accounting for $63.90 \%$ of the market. The overall sales concentration of new energy logistics vehicles is relatively high, sales figures are shown in Table 1.

Table 1. New energy logistics vehicle sales city ranking Top10

\begin{tabular}{|c|c|c|c|}
\hline & \multicolumn{3}{|c|}{} \\
\hline Rank & Cities in sales of new energy logistics vehicles in 2020 \\
\hline $\mathbf{1}$ & Shenzhen & 12858 & $\begin{array}{c}\text { Market } \\
\text { share }\end{array}$ \\
\hline $\mathbf{2}$ & Chengdu & 5222 & $9.00 \%$ \\
\hline $\mathbf{3}$ & Guangzhou & 3894 & $6.71 \%$ \\
\hline $\mathbf{4}$ & Nanjing & 3265 & $5.62 \%$ \\
\hline $\mathbf{5}$ & Beijing & 2550 & $4.39 \%$ \\
\hline $\mathbf{6}$ & Zhengzhou & 2066 & $3.56 \%$ \\
\hline $\mathbf{7}$ & Changsha & 1902 & $3.28 \%$ \\
\hline $\mathbf{8}$ & Suzhou & 1867 & $3.22 \%$ \\
\hline $\mathbf{9}$ & Chongqing & 1866 & $3.21 \%$ \\
\hline $\mathbf{1 0}$ & Xiamen & 1602 & $2.76 \%$ \\
\hline
\end{tabular}

On the whole, the hot-selling city of new energy logistics vehicles is still the original key city, and the relevant preferential policies is one of the important factors affecting the sales of new energy logistics vehicles.

\section{Cost Advantage Analysis of New Energy Logistics Vehicle}

The new energy logistics vehicle basically meets the normal demand of urban logistics. Because of the low cost of use and maintenance, the new energy logistics vehicle has a large cost advantage in theory. By TCO, this part calculates the price orientation of the new energy logistics vehicle without subsidy.

\subsection{TCO Analysis framework}

Freight car TCO cost consists of five parts: purchase cost, use cost, maintenance cost, residual value and opportunity cost.

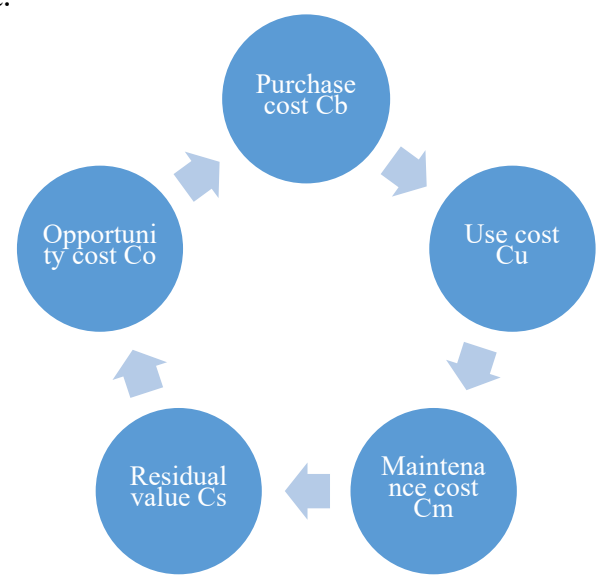

Fig. 2. Analysis Model of Truck

According to the analysis structure of figure 2 , the whole life cycle cost $(\mathrm{Ct})$ calculation formula of freight car is as follows:

$$
\mathrm{Ct}=\mathrm{Cb}+\mathrm{Cu}+\mathrm{Cm}-\mathrm{Cs}+\mathrm{Co}
$$

When the whole life cycle cost of a certain type of truck is the same, the positioning of the initial price of the new energy truck determines its economic advantage.

\subsection{Basic data determination}

(1) Determination of comparative analysis models

ICE and BEV versions of the same model: the Jianghuai Junling V6 model with a total quality of 4.5 tons is selected, and the Jianghuai Shuai Ling i5 pure electric model is selected for the EV model.

(2) Acquisition link

The vehicle purchase adopts the full purchase method. The TCO economy of new energy trucks and traditional fuel trucks will be calculated in TCO analysis under the condition of full subsidy withdrawal. New energy vehicles can still enjoy purchase tax exemption and exemption from vehicle and ship tax. The cost of the purchase link is calculated as shown in Table 2 . 
Table. 2 ICE and BEV details of car purchase costs

\begin{tabular}{|c|c|c|c|c|c|}
\hline $\begin{array}{c}\text { Class of } \\
\text { vehicle }\end{array}$ & Representative type & $\begin{array}{c}\text { Power } \\
\text { resources }\end{array}$ & $\begin{array}{c}\text { No subsidy } \\
\text { price,10,000 } \\
\text { yuan }\end{array}$ & $\begin{array}{c}\text { Purchase tax, } \\
\mathbf{1 0 , 0 0 0} \text { yuan }\end{array}$ & $\begin{array}{c}\text { Car and ship } \\
\text { tax, 10,000 } \\
\text { yuan }\end{array}$ \\
\hline $\begin{array}{c}\text { Traditional } \\
\text { fuel light truck }\end{array}$ & Jianghuai Junling V6 & Diesel fuel & 10.80 & 0.92 & 0.03 \\
\hline $\begin{array}{c}\text { New Energy } \\
\text { Light Card }\end{array}$ & $\begin{array}{c}\text { Jianghuai Shuai Ling } \\
\text { i5 }\end{array}$ & $\begin{array}{c}\text { Iron } \\
\text { carbonate } \\
\text { lithium } \\
\text { battery 96.77 } \\
\text { degrees }\end{array}$ & 26.00 & 1.11 & 0 \\
\hline
\end{tabular}

(3) Use links

The main cost difference of the use link is fuel cost. Diesel price 0 selected the average price of 6.40 yuan per liter in all provinces of the country, charging electricity is 0.9 yuan per $\mathrm{kWh}$.

According to Jianghuai automobile after-sales service policy, the quality guarantee period of key system of new energy vehicle is 5 years. New energy truck maintenance is relatively simple, each time only the battery, circuit systems and connectors for inspection and maintenance. All vehicles are subject to regular maintenance. It is set that traditional fuel vehicles shall be maintained strictly every $5000 \mathrm{~km}$ (replacement and maintenance of oil, engine filter, air filter, etc.). Pure electric vehicles shall regularly maintain batteries, circuits, connectors, etc. Total use link costing is shown in Table 3, and the three-electric cost forecast for new energy trucks is shown in Figure 3.

Table. 3 ICE and BEV cost breakdown

\begin{tabular}{|c|c|c|c|c|}
\hline $\begin{array}{c}\text { class of } \\
\text { vehicle }\end{array}$ & $\begin{array}{c}\text { Insurance, } \\
10,000 \\
\text { yuan }\end{array}$ & $\begin{array}{c}\text { Annual } \\
\text { cost of } \\
\text { use, } \\
10,000 \\
\text { yuan }\end{array}$ & $\begin{array}{c}\text { Annual } \\
\text { maintenance } \\
\text { costs, } \\
10,000 \text { yuan }\end{array}$ & $\begin{array}{c}\text { Annual } \\
\text { cost of } \\
\text { use, } \\
10,000 \\
\text { yuan }\end{array}$ \\
\hline $\begin{array}{c}\text { Traditional } \\
\text { fuel light } \\
\text { truck }\end{array}$ & 0.19 & 5.72 & 0.56 & 6.5 \\
\hline $\begin{array}{c}\text { New Energy } \\
\text { Light Card }\end{array}$ & 0.19 & 2.59 & 0.10 & 2.88 \\
\hline
\end{tabular}

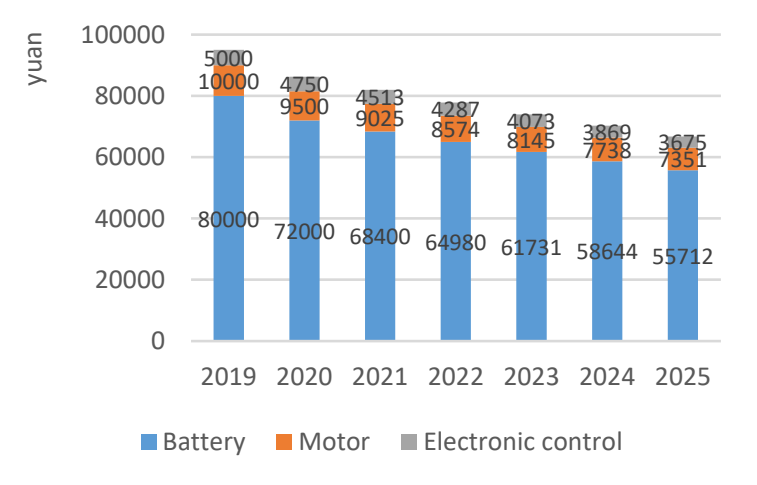

Fig. 3. Cost Forecast for New Energy Truck

(4) Average battery life
The average battery life is calculated by two methods. First, calculate the average life cycle by battery life, battery cycle life: lithium iron phosphate battery is 2000 2500 times, the highest 2500 times. Charging times: according to the survey, a car needs to charge once a day on average. Therefore, battery life $=$ battery cycle life $:$ charging times $\div 365$ days, that is, $12500 \div 365=6.85$ years.

Second, calculate the average life cycle by mileage, the average daily mileage of logistics vehicles is $100 \sim 200 \mathrm{k}$ $\mathrm{m}$, and the scrap mileage of operating vehicles is 600000 $\mathrm{km}$. Therefore, battery life $=$ scrap mileage $\div 365$ days, that is, $6000000 \div 200 \div 365=8.22$ years. The lowest value of the two methods is shown here for 7 years (rounded).

\subsection{TCO Results calculated}

In order to compare the value of funds in different periods, only by converting them into the present value (that is, the value of 0 years in the initial year) can the funds in different periods have a common starting point and be comparable. The following formula is used:

$$
\begin{gathered}
P_{1}=P_{\operatorname{Pr} \text { ice }}+A \times \frac{(1+i)^{n}-1}{(1+i)^{n} \times i} \\
A_{i}=P_{1} \times \frac{(1+i)^{n}}{(1+i)^{n} \times i}
\end{gathered}
$$

Note: the $A_{i}$ is the annual TCO, $n_{\text {is the year, the }}$ $i$ is the annual interest rate of $3 \%$.

The service life of the ICE is 10 years and the service life of the BEV is 7 years. Through formula calculation, the average annual TCO of BEV is 70600 yuan, which has more cost advantage than that of ICE 77700 yuan.

\section{Summary}

With the strengthening of environmental awareness and the progress of information technology, developing Green Logistics is an inevitable trend, green, science and technology are important characteristics of logistics development in the future. The promotion and application of new energy logistics vehicles will become one of the important ways to develop green logistics. The new energy logistics vehicle not only has the green environmental protection characteristic, meets the overall requirements of developing green logistics, but also has a higher level of intelligence. Putting new energy logistics 
vehicles into urban logistics is not only helpful to solve the problems in distribution, but also in line with the concept of urban scientific management and green sustainable development.

\section{References}

1. Pang, L.W., Zheng, M.W., Wu, Y.H., Jv, F.(2020) Discussion on Urban Logistics Distribution Network from Low Carbon Perspective. J. Modern Marketing, 05: 146-147.

2. Rogo Study. (2019) Research Report on Green Freight Forwarding in Chinese Cities 2019. http://www.logclub.com/front/lc_report/get_report_i nfo/57-96.

3. Tram resources. (2021) 2020 new energy logistics vehicle city sales ranking. http://www.evpartner.com/news/135/detail55196.html.

4. Ding, Q.(2020) Analysis on TCO Competitiveness of New Energy Logistics Vehicle. J. Special Purpose Vehicle,03:65-67. 